\title{
O SAPATEIRO de APELES: O STF APÓs 1988
}

Autor: Cristiano de Jesus Pereira Nascimento. Juiz Federal. Mestrando em Filosofia do Direito na Pontifícia Universidade Católica de São Paulo - PUC/SP.

\section{RESUMO:}

O presente artigo examina o protagonismo político do Supremo Tribunal Federal após a Constituição brasileira de 1988, no contexto de expansão global da influência do poder judiciário. Sustenta que a influência excessiva do poder judiciário fragiliza o processo democrático. A resolução de disputas pela via judicial exige conhecimento especializado. A burocracia judicial não pode ser o ambiente exclusivo e final de todas as decisões políticas importantes.

Democracia - Controle de constitucionalidade - Legitimidade - Poder Judiciário - Supremo Tribunal Federal.

\begin{abstract}
:
This article studies the Supremo Tribunal Federal's political protagonism after the brazilian Constitution of 1988, in the context of the global expansion of judicial power. It defends that the excessive influence of the judicial power weakens the democratic process. The judicial resolution disputes demands professional expertise. The judicial bureaucracy can not be the exclusive and final spot for all important political decisions.
\end{abstract}

Democracy - Judicial review - Legitimacy - Judicial Power - Supremo Tribunal Federal 


\section{O entusiasmo do Supremo Tribunal Federal}

Conta-se que Apeles, célebre pintor grego da idade antiga, era obcecado com a perfeição e aplicava o máximo cuidado em cada detalhe de seus quadros. Certa feita, enquanto trabalhava uma figura humana que necessitava usar sandálias, ocorreu-lhe consultar um sapateiro, a fim de retratar da maneira mais realista possível o adereço. O sapateiro, envaidecido com a consulta, e tendo verificado que o artista emendara o desacerto, se aventurou a dar opiniões sobre a anatomia do joelho. Foi então que Apeles, furioso com o impertinente, disse a frase histórica: "Não suba o sapateiro acima da chinela!".

Alguém já disse que a tentação do sapateiro é a mais comum entre os humanos. ${ }^{1}$ Um observador contemporâneo das instituições brasileiras poderia dizer que a tentação é irresistível também para o Supremo Tribunal Federal.

Após a Constituição de 1988, as normas constitucionais ganharam centralidade no discurso jurídico. Simultaneamente, verificou-se um notável incremento da influência do Judiciário no processo político decisório. Os juízes e as cortes superiores passaram a exercer um papel muito mais relevante e decisivo. O órgão de cúpula do judiciário, sobretudo, abandonou o papel coadjuvante desempenhado antes da Constituição de 1988 (e durante toda a história institucional do Brasil independente, desde o império) e assumiu, em muito pouco tempo, verdadeiro protagonismo no processo político-institucional, exercendo com entusiasmo poderes novos e mais dilatados.

O órgão de cúpula do judiciário brasileiro jamais se sentiu tão à vontade para neutralizar as decisões do parlamento, por intermédio do controle de constitucionalidade, em sua modalidade difusa ou concentrada. O Supremo tem desenvolvido uma atuação marcadamente ativista, que reforça o seu próprio poder em detrimento, principalmente, do espaço de atribuições do Congresso. Os exemplos são numerosos: interpretação conferida à fidelidade partidária, cassação de mandatos parlamentares em ação

\footnotetext{
${ }^{1}$ SARAMAGO, José. História do cerco de Lisboa. São Paulo: Companhia das Letras, 2008.
} 
penal, reconhecimento das uniões estáveis entre pessoas do mesmo sexo, tese da mutação constitucional do art. 52, X, desrespeito ao poder de agenda do Congresso na votação dos royalties do petróleo, dentre tantos outros casos. ${ }^{2}$

Há pouca ou nenhuma deferência às decisões do Parlamento. Há nenhuma deferência, por exemplo, quando se analisa o que fez o Supremo na Ação Direta de Inconstitucionalidade ${ }^{\circ}$ 5.017, na qual se questiona a constitucionalidade da Emenda Constitucional n. 73, de 2013, que modificou a estrutura do judiciário federal para criar quatro novos Tribunais Federais. No recesso, em decisão monocrática, o presidente do Supremo concluiu que a emenda padecia de inconstitucionalidade e suspendeu a decisão do Congresso. A decisão monocrática, três longos anos depois de prolatada, sequer foi submetida ao colegiado.

É certo que a expansão do poder judiciário, e do controle judicial das leis, é um fenômeno global. ${ }^{3}$ Conforme observa Tom Ginsburg, "in recent decades, judicial review has expanded around the globe from the United States, Western Europe, and Japan to become a regular feature of constitucional design in Africa and Asia". ${ }^{4}$ Ran Hirschl, por sua vez, avança a afirmação de que, nos últimos anos, o mundo tem testemunhado uma assombrosa e rápida transição para o que se pode chamar de “juristocracia”, com uma transferência de poder sem precedentes das instituições representativas para o judiciário. $^{5}$

Ainda que se trate de fenômeno global, não seria exagerado dizer que, no Brasil, essa expansão atingiu os níveis mais elevados possíveis. Nos Estados Unidos, por exemplo, onde a corte suprema tem

\footnotetext{
${ }^{2}$ Os precedentes são, pela ordem, respectivamente: ADI no. 3999/DF; AP nº. 470/MG, ADI nº. 4.277/DF, Recl. 4.335/AC e MS no 31816/RJ.

3 TATE, Neal; VALLINDER, Torbjörn (coord.). The global expansion of judicial power. New York: New York University Press, 1995.

4 GINSBURG, Tom. Judicial review in new democracies: constitucional courts in asian cases. Cambridge: Cambridge University Press, 2003, p. 261.

${ }^{5}$ HIRSCHL, Ran. Towards juristocracy: the origins and consequences of the new constitucionalism. Cambridge: Harvard University Press, 2007. Confira-se, no original: “[o]ver de past few years the world has witnessed an astonishingly rapid transition to what may de called juristocracy. Around the globe, in more than eighty countries and in several supranational entities, constitucional reform has transferred an unprecedented amount of power from representative institutions to judiciaries".
} 
imenso poder, e onde se construiu o mecanismo do judicial review que se difundiu pelo mundo, simplesmente não existe possibilidade de controle constitucional de Emenda à Constituição. Ao longo de mais de duzentos anos, apenas 150 leis federais norte-americanas foram declaradas inconstitucionais. ${ }^{6}$

No Brasil, contudo, pode-se constatar uma banalização do controle dos atos do parlamento (provavelmente sem paralelo nas democracias ocidentais), onde se admite que decisão individual e provisória, lançada quase imediatamente em seguida à promulgação de uma emenda constitucional, suplante uma manifestação de maioria qualificada do Congresso Nacional. O episódio constitui um exemplo eloqüente do entusiasmo, da confiança exagerada nas próprias capacidades, que tem marcado a atuação do Supremo nos últimos anos.

O objeto deste trabalho é indicar as possíveis causas e consequiências dessa nova postura do órgão de cúpula do Judiciário brasileiro. E o risco para a democracia que essa postura pode significar.

\section{Deliberação judicial: déficit democrático}

A idéia atualmente vitoriosa na doutrina constitucionalista aponta o judiciário como o depositário da confiança institucional para velar pelos direitos individuais, que poderiam ser eliminados caso estivessem confiados exclusivamente ao parlamento, sujeito ao domínio eventual de maiorias irracionais ou preconceituosas.

Inevitável reconhecer que o senso comum teórico aceita que o controle judicial é uma decorrência lógica da rigidez e supremacia da constituição. Luís Roberto Barroso sintetizou essa crença nos seguintes termos:

\footnotetext{
${ }^{6}$ GREENHOUSE, Linda. The U.S. Supreme Court: a very short introduction. Oxford: Oxford University Press, 2012. Confirase, à p. 12: “(...) the Court has lost its early reticence. It has declared acts of Congress unconstitucional more than 150 times". É notável que a autora indique esse número, extremamente baixo por se tratar de período histórico que ultrapassa duzentos anos, como prova de ausência de timidez da corte norte-americana.
} 
É fora de dúvida que a tese da legitimidade do controle de constitucionalidade foi amplamente vitoriosa, assim no debate acadêmico como na prática jurisprudencial (...). Seu êxito deveu-se a argumentos de lógica aparentemente irrefutável. (...) A Constituição, obra do poder constituinte originário e expressão mais alta da soberania popular, está acima do poder constituído, subordinando inclusive o legislador. Se a Constituição tem status de norma jurídica, cabe ao Judiciário interpretá-la e aplicá-la. ${ }^{7}$

Contudo, o tipo de controle que se deseja não é uma questão de lógica, mas uma questão prática e política, conforme ressalta Virgílio Afonso da Silva. Ainda que o controle de constitucionalidade seja conveniente, "porque talvez seja prudente desconfiar dos poderes e prever mecanismos para controlálos, esse controle não precisa ser necessariamente judicial". ${ }^{8}$ Há exemplos de democracias maduras que durante muito tempo não adotaram o modelo norte-americano nem o austríaco de controle judicial. Com efeito, a França, até 2008, não possuía controle judicial de constitucionalidade a posteriori. ${ }^{9}$

Como adverte John Hart Ely, uma maioria sem limites é de fato algo perigoso, mas é preciso um esforço heróico para deduzir, a partir dessa constatação, que o controle por agentes públicos não eleitos seja a resposta apropriada numa república democrática ${ }^{10}$. A solução judicial não é a única. Não há nenhuma garantia de que seja a melhor. E certamente não será a mais democrática.

Para Jeremy Waldron ${ }^{11}$, o controle de constitucionalidade pelo Judiciário merece duas críticas principais. Em primeiro lugar, porque é democraticamente ilegítimo. Em segundo lugar, porque não haveria fundamento para supor que os direitos estão mais bem protegidos por essa prática.

\footnotetext{
${ }^{7}$ BARROSO, Luís Roberto. O controle de constitucionalidade no direito brasileiro: exposição sistemática da doutrina e análise crítica da jurisprudência. São Paulo: Saraiva, 2008, p. 55.

${ }^{8}$ SILVA, Virgílio Afonso da. "O STF e o controle de constitucionalidade: deliberação, diálogo e razão pública". Revista de Direito Administrativo 250, 2009, p. 202.

${ }^{9}$ Ibidem, p. 206.

${ }^{10}$ ELY, John Hart. Democracy and distrust: a theory of judicial review. Cambridge: Harvard University Press, 1980, p. 8.

${ }^{11}$ WALDRON, Jeremy. "The Core of the Case Against Judicial Review". Yale Law Journal, Vol. 115 (6), 2006.
} 
Quanto ao segundo ponto, uma vista de olhos na história da jurisprudência americana, que pode oferecer decisões ao longo de dois séculos, é bastante para demonstrar que o judiciário funciona muitas vezes como obstáculo à concretização de direitos. ${ }^{12}$

Waldron sustenta que não há nenhuma razão para preferir uma votação por maioria, realizada entre um pequeno número de juízes que não foram eleitos nem podem ser facilmente cobrados por suas decisões, à votação por maioria realizada num colegiado mais amplo, eleito pelo povo. ${ }^{13}$ Mesmo quando os juízes são eleitos (como na maioria das magistraturas estaduais nos Estados Unidos), as atividades das cortes não são normalmente conduzidas de acordo com um ethos de representação e prestação de contas eleitoral, como nas atividades legislativas. ${ }^{14}$

A crítica de Waldron ressalta um elemento crucial da democracia: o direito que tem o cidadão de participar das decisões coletivas, de ser tratado como um igual no processo político decisório. Ilustra a perplexidade de se ver alienado do processo decisório, quando a palavra final é transferida para um corpo profissional de poucos juízes, com a seguinte pergunta, que se pode fazer o cidadão inconformado: “Como eles podem excluir a minha voz dessa decisão, que me afeta e à qual estou sujeito?”. ${ }^{15}$

A mesma perplexidade pode ser expressada em outros termos: por que onze homens e mulheres devem decidir determinado assunto, usando a mesma regra de maioria, em detrimento de um corpo eleito, que representa toda a coletividade? Para Waldron, a decisão sobre os direitos não deve ser reservada a uma elite judiciária, pois o direito à participação é o direito dos direitos. ${ }^{16}$

É preciso reconhecer que o modelo institucional vigente já permite, num certo sentido, a interferência indireta no controle judicial de leis e atos normativos, tanto pelo Legislativo como pelo Executivo, uma vez que os componentes do Supremo Tribunal Federal são escolhidos e nomeados pelo

\footnotetext{
${ }^{12}$ Esse o ponto de vista, lastreado em profundo conhecimento da história constitucional americana, de Mark Tushnet, na obra Taking the Constitution away from the courts. Princeton: Princeton University Press, 2000.

${ }^{13}$ WALDRON, Jeremy. "The Core of the Case Against Judicial Review". Yale Law Journal, Vol. 115 (6), 2006, p. 1353.

${ }^{14}$ Ibidem, p. 1363.

${ }^{15}$ Ibidem, p. 1375.

${ }^{16}$ SILVA, Virgílio Afonso da. "O STF e o controle de constitucionalidade: deliberação, diálogo e razão pública". Revista de Direito Administrativo 250, 2009, p. 204..
} 
Presidente da República e necessitam de aprovação do Senado Federal para tomarem assento no Tribunal.

Mark Tushnet, discorrendo sobre o modelo norte-americano, que, no ponto, não difere do brasileiro, expõe exatamente essa visão: “o que a Suprema Corte diz a respeito dos nossos direitos depende, de uma maneira sofisticada, do estado de nossa política". ${ }^{17}$ E observa que os juízes são parte do sistema político na medida em que eles ingressam na Corte "porque um presidente pensa que ao colocar na Corte essa pessoa, ao invés daquela, estará promovendo seus interesses políticos de curto e de longo prazo (...) Os senadores votam a favor ou contra um indicado sob considerações políticas semelhantes". ${ }^{18}$

Assim, por um sofisticado mecanismo de freios e contrapesos, a competência do Supremo Tribunal Federal para dizer a última palavra acerca de controvérsias constitucionais não estaria totalmente imune à vontade popular, visto que os representantes do povo exercem o controle sobre as indicações de juízes e poderiam, nessa oportunidade, assegurar a vitória de determinada visão ideológica sobre direitos fundamentais. A sabatina também poderia ser um instrumento do Parlamento para selecionar juízes com perfil de moderação e deferência às decisões do Congresso.

Por outro lado, no modelo atual, a própria Constituição Federal permite que o Parlamento renove proposições legislativas que já foram rejeitadas pelo Supremo Tribunal Federal, pois as decisões do Supremo Tribunal Federal nas ações de inconstitucionalidade e nas ações declaratórias de constitucionalidade não produzirão efeito vinculante relativamente ao Poder Legislativo, conforme se

\footnotetext{
17 TUSHNET, Mark. Why the Constitution matters. New Haven: Yale University Press, 2010, p. 4. O texto no original é o seguinte: "What the Supreme Court says our rights are depends in a complicated way on the state of our politics".

${ }^{18}$ Ibidem, pp. 4-5. O texto no original é o seguinte: "They get to the Court because a president thinks that putting this person rather than the other on the Court will promote some of the president's short-and long-term political interests. (...) Senators vote for or against a nominee on similar political grounds".
}

http://revistasapereaude.org/index.php/edicoes/ano-5-volume-2-setembro-2016

D.O.I: $10.20523 /$ sapereaude-ano5-vol-2-pg-1-15 
pode extrair do $\S 2^{\mathbf{0}}$ do art. 102 da Constituição ${ }^{19}$. O próprio Supremo Tribunal Federal firmou jurisprudência nesse sentido. $^{20}$

Ademais, a Constituição prevê uma forma de participação do parlamento ao prever que o Senado Federal pode suspender a execução, no todo ou em parte, de lei declarada inconstitucional por decisão definitiva do Supremo Tribunal Federal. Isso sempre significou, na tradição constitucional brasileira, que a decisão do Supremo no controle difuso de constitucionalidade só terá efeitos gerais se houver a atuação do Senado, chancelando o juízo de inconstitucionalidade da Corte. ${ }^{21}$

Todos esses mecanismos de controle, porém, não estão evitando embates sucessivos entre o Congresso e o Supremo Tribunal Federal. Inclusive porque o Supremo Tribunal Federal tem avançado em direção à ampliação de suas próprias competências. Confira-se, por exemplo, o intenso debate sobre a competência do Senado Federal ao longo do julgamento da Reclamação nº 4.335/AC, de relatoria do Ministro Gilmar Mendes, com alguns votos já proferidos no sentido de que a teria havido mutação constitucional ao longo do tempo e a resolução do Senado Federal teria se transformado apenas num mecanismo de publicidade das decisões do Supremo Tribunal Federal. ${ }^{22}$ Para Clara da Mota Santos,

\footnotetext{
${ }^{19}$ Eis a redação do preceito constitucional: " $\$ 2^{\circ}$ As decisões definitivas de mérito, proferidas pelo Supremo Tribunal Federal, nas ações diretas de inconstitucionalidade e nas ações declaratórias de constitucionalidade produzirão eficácia contra todos e efeito vinculante, relativamente aos demais órgãos do Poder Judiciário e à administração pública direta e indireta, nas esferas federal, estadual e municipal. (Redação da EC 45/2004)”. Verifica-se que a Constituição deliberadamente omite a menção ao Poder Legislativo.

${ }^{20}$ Rcl 2.617-AgR, Rel. Min. Cezar Peluso, julgamento em 23-2-2005, Plenário, DJ de 20-5-2005: “A eficácia geral e o efeito vinculante de decisão, proferida pelo STF, em ação direta de constitucionalidade ou de inconstitucionalidade de lei ou ato normativo federal, só atingem os demais órgãos do Poder Judiciário e todos os do Poder Executivo, não alcançando o legislador, que pode editar nova lei com idêntico conteúdo normativo, sem ofender a autoridade daquela decisão."

${ }^{21} \mathrm{O}$ art. 52 da Constituição trata das competências privativas do Senado Federal, e contém o seguinte inciso: " $X$ - suspender a execução, no todo ou em parte, de lei declarada inconstitucional por decisão definitiva do Supremo Tribunal Federal".

${ }^{22}$ Em julgamento realizado no ano de 1961, discutindo a mesma questão, o Ministro Carlos Medeiros Silva lançou as seguintes observações: "Repugna a tudo quanto se possa conceber como apropriado a uma assembleia e a uma assembleia das características do Senado, ver nele mero órgão executor do Supremo Tribunal Federal. Há questões que a solução é percebida, nitidamente percebida, antes mesmo de se encontrar a sua fundamentação. Essa é uma delas. Atribuir ao Senado papel mecânico, faze-lo autômato, transformá-lo em carimbo, meirinho, cartório ou porteiro de auditórios, não significa apenas atribuir-lhe função absolutamente subalterna, mas, e, especialmente, sem qualquer significação e utilidade, tarefa que poderia ser desempenhada, com proficiência e vantagem, por qualquer funcionário da secretaria do Supremo Tribunal Federal”. RTJ 38/61. Referência colhida na dissertação de mestrado de Clara da Mota Santos: Ativismo judicial e mutação constitucional: uma proposta de reação democrática do controle difuso de constitucionalidade à tese de sua “objetivação”. Brasília: UNB, 2013.
} 
"essa tese de mutação constitucional é parte de uma guinada maior de ativismo por parte do STF, talvez. evidenciando umas das suas facetas mais perigosas, a do ativismo alargador de competências". 23

Por outro lado, o nosso sistema não possui um mecanismo institucionalizado para que, no limite da divergência, o Parlamento e o Executivo respondam, em um espaço de tempo curto, às decisões do $\mathrm{STF}^{24}$

Seja como for, Waldron parece ter razão ao apontar que não se trata de negar a existência de elementos democráticos na atuação do Judiciário, mas sim de reconhecer que esse controle é incomparavelmente inferior ao controle que se tem sobre a atuação do Parlamento, o qual, insista-se, atua com um ethos de representatividade e prestação de contas.

A própria linguagem técnica utilizada na deliberação judicial já implica no alheamento, da maioria dos cidadãos, do debate público de questões que tocam a todos. A limitação do debate público a partir da transferência dele para a esfera judicial também não passou despercebida nem mesmo a Luis Roberto Barroso, um entusiasta do ativismo do Supremo: “o mundo do direito tem categorias, discurso e métodos próprios de argumentação. O domínio desse instrumental exige conhecimento técnico e treinamento específico, não acessíveis à generalidade das pessoas. A primeira conseqüência drástica da judicialização é a elitização do debate e a exclusão dos que não dominam a linguagem nem têm acesso aos locus de discussão jurídica". ${ }^{25}$

Esse efeito excludente, para Pierre Bourdieu, é intrínseco à deliberação judicial, à instituição de um "espaço judicial”:

\footnotetext{
${ }^{23}$ SANTOS, Clara da Mota. Ativismo judicial e mutação constitucional: uma proposta de reação democrática do controle difuso de constitucionalidade à tese de sua "objetivação. Dissertação de mestrado, Universidade de Brasília, 2013.

${ }^{24}$ SOUZA, Jorge Munhós de. "Diálogo institucional: em algum lugar entre as teorias da supremacia". in As novas faces do ativismo judicial, (André Luiz Fernandes Fellet/ Daniel Giotti de Paula/ Marcelo Novelino, orgs.). Salvador: Editora Juspodivm, 2011, p. 344. O autor ainda lança as seguintes observações: "enquanto os sistemas dialógicos permitem que os ramos políticos revertam decisões tomadas pelos demais atores em um prazo curto, o modelo de supremacia judicial até permite que ocorram reversões, mas essas somente se processarão em um período de tempo mais estendido."
}

${ }^{25}$ BARROSO, Luis Roberto. Constituição, democracia e supremacia judicial: direito e política no Brasil contemporâneo, RFD- Revista da Faculdade de Direito- UERJ, v. 2, n. 21, jan./jun. 2012.

http://revistasapereaude.org/index.php/edicoes/ano-5-volume-2-setembro-2016

D.O.I: 10.20523/sapereaude-ano5-vol-2-pg-1-15 
(...) a instituição de um "espaço judicial implica a imposição de uma fronteira entre os que estão preparados para entrar no jogo e os que, quando nele se acham lançados, permanecem de fato dele excluídos, por não poderem operar a conversão de todo o espaço mental - e, em particular, de toda a postura linguística - que supõe a entrada neste espaço social. A constituição de uma competência propriamente jurídica, mestria técnica de um saber científico frequentemente antinômico das simples recomendações do senso comum, leva à desqualificação do sentido de equidade dos não-especialistas e à revogação da sua construção espontânea dos fatos (...) O desvio entre a visão vulgar daquele que se vai tornar num “justiciável”, quer dizer, num cliente, e a visão científica do perito, juiz, advogado, conselheiro jurídico, etc., nada tem de acidental; ele é constitutivo de uma relação de poder. ${ }^{26}$

Quando o debate público se desloca para o espaço judicial ocorre uma perda imediata e necessária da capacidade de participação. Os cidadãos já não são mais donos das decisões sobre o próprio destino, delegando-as a um corpo de profissionais. A mediação do debate realizada pelo judiciário implica "a perda da relação de apropriação direta e imediata da sua própria causa: perante um pleiteante ergue-se um poder transcendente" 27.

\section{Deliberação judicial: déficit epistêmico}

\footnotetext{
${ }^{26}$ BOURDIEU, Pierre. O poder simbólico. Rio de Janeiro: Bertrand Brasil, 2007, p. 225.

${ }^{27}$ Ibidem, p. 229.
} 
Sob outro prisma, invocando a autoridade de Aristóteles, Waldron sustenta a convicção de que "as pessoas agindo como um só corpo são capazes de elaborar decisões melhores, pela soma de seus conhecimento, experiência, e intuição, mais do que qualquer subconjunto de pessoas agindo como um corpo e somando o conhecimento, experiência, e intuição dos membros desse subconjunto"28.

A idéia de que o Parlamento participe de forma relevante do procedimento de invalidação de atos normativos, ainda que menos influente, conta com o respaldo de autores extremamente críticos à revisão judicial, pelo seu caráter supostamente antidemocrático. Parte desses autores defendem que o Poder Legislativo possui condições superiores à do Judiciário para oferecer decisões de qualidade, por intermédio de procedimento que, ao mesmo tempo, preserve os direitos fundamentais das minorias.

As potencialidades do Poder Legislativo, ainda que não seja tema corrente na doutrina brasileira, têm merecido intensa reflexão da doutrina estrangeira. Nos Estados Unidos, por exemplo, Adrian Vermeule ressalta a superioridade epistêmica do Parlamento em comparação com as limitadas capacidades dos órgãos judiciários:

The relatively small number of judges on relevant courts, their limited informational base, their Professional homogeneity, and their generalist rather than specialized skills, all ensure that judicial reason is itself sharply limited. (...) these deficits are not offset by the judges' ability to call upon the purported collective wisdom of past judges or of social traditions and customs (...) legislatures possess epistemic advantages by virtue of their diversity, their tools for gathering and processing information, and the sheer number of their members (...) under a broad range of conditions, legislatures and executive bodies do indeed possess superior epistemic capacities, or so I argue throughout. (...) Precisely because of the limits of human reason, large modern legislatures,

\footnotetext{
${ }^{28}$ The dignity of legislation. Cambridge: Cambridge University Press, 2007, p. 94. O original traz o seguinte: "the people acting as a body are capable of making better decisions, by pooling their knowledge, experience, and insight, than any subset of the people acting as a body and pooling the knowledge, experience, and insight of the members of the subset".
} 
with their numerous memberships, professional and ideological diversity, complex internal structures for processing information, and abundant informational resources, are epistemically formidable institutions ${ }^{29}$.

Vermeule vai ao ponto de sugerir que a Suprema Corte norte-americana deveria ter um ou mais juízes que não fossem advogados (ou pelo menos não apenas advogados). ${ }^{30}$

Apesar de crítico severo de Vermeule, Richard Posner ressalta as mesmas limitações cognitivas do Poder Judiciário. Eis as reflexões de Posner, dirigidas originalmente a juízes de cortes federais norteamericanas, entretanto aplicáveis perfeitamente ao Supremo Tribunal Federal, que, ao contrário da Suprema Corte norte-americana, não possui a discricionariedade para selecionar casos:

No judge of such a court can be an expert in more than a small fraction of the fields of law that generate the appeals that he must decide, or can devote enough time to an individual case to make himself, if only for the moment (knowledge obtained by cramming is quickly forgotten), an expert in the field out of which the case arises. Unlike the Supreme Court, moreover, the courts of appeals must decide all the dispositive issues presented by a case, however many there are, and a single case may present issues in several different fields of law. A judge is a generalist who writes an opinion under pressure of time in whatever case, in whatever field of law, is assigned to him. ${ }^{31}$

\footnotetext{
${ }^{29}$ VERMEULE, Adrian. Law and the limits of reason, New York: Oxford University Press, 2009, p. 2-4.

${ }^{30}$ VERMEULE, Adrian. Law and the limits of reason, New York: Oxford University Press, 2009, p. 16. Eis o trecho que interessa: "Supreme Court should have one or more justices who are not lawyers (or at least not only lawyers), and who thus would bring their nonlegal expertise to bear on statutory as well as constitutional cases". Numa tradução livre: "A Suprema Corte deveria ter um ou mais juízes que não são advogados (ou ao menos não apenas advogados), e que assim trariam sua expertise extrajurídica para enfrentar interpretação de leis, tanto quanto casos constitucionais".

${ }^{31}$ POSNER, Richard. How judges think, Cambridge: Harvard University Press, 2010.
} 
O legislativo, por ser um corpo mais amplo, formado por membros das mais variadas formações profissionais, tem mais condições de processar informações e produzir uma decisão bem informada, o que aumenta a probabilidade de que seja uma decisão melhor. E a decisão também tem mais chances de contemplar as diferentes visões presentes na sociedade, visto que o corpo parlamentar sofre a influência dessas visões muito mais do que um corpo de juristas profissionais.

\section{Conclusão}

Há um otimismo ingênuo sobre as capacidades do judiciário, e sobretudo do Supremo. ${ }^{32}$ Esse otimismo encontra, no Brasil, terreno fértil para prosperar, visto que a elitização do debate público (consequência natural da judicialização do debate) está em harmonia com uma ideia básica, fundamental, da mentalidade política brasileira: a crença na ignorância e na incapacidade do povo brasileiro para decidir o seu próprio destino.

Há uma arraigada convicção, na cultura política do país, de que o povo deve ser governado de cima. O povo deve ser conduzido, não conduzir (o inverso da formulação de Lincoln em Gettysburg). Esse tipo de mentalidade forneceu o ambiente ideológico para o golpe de 64, que entregou o poder a um corpo de “competentes" e "puros", como sacerdotes responsáveis pelo destino do povo.

A concentração sem precedentes de poderes decisórios no Supremo Tribunal Federal é o velho hábito de subtrair do povo o poder de decidir por si mesmo, entregando esse poder a uma corporação de “competentes”, “técnicos”, “puros”. É a mesma idéia, vestida com roupas novas e sapatos reluzentes.

\section{BIBLIOGRAFIA}

\footnotetext{
${ }^{32}$ BARROSO, Luís Roberto. A razão sem voto: o Supremo Tribunal Federal e o governo da maioria. Revista Brasileira de Políticas Públicas, Brasília, v. 5, Número Especial, 2015.
} 
BARROSO, Luís Roberto. O controle de constitucionalidade no direito brasileiro: exposição sistemática da doutrina e análise crítica da jurisprudência. São Paulo: Saraiva, 2008

BARROSO, Luis Roberto. Constituição, democracia e supremacia judicial: direito e política no Brasil contemporâneo, RFD- Revista da Faculdade de Direito- UERJ, v. 2, n. 21, jan./jun. 2012

BARROSO, Luís Roberto. A razão sem voto: o Supremo Tribunal Federal e o governo da maioria. Revista Brasileira de Políticas Públicas, Brasília, v. 5, Número Especial, 2015

BOURDIEU, Pierre. O poder simbólico. Rio de Janeiro: Bertrand Brasil, 2007

ELY, John Hart. Democracy and distrust: a theory of judicial review. Cambridge: Harvard University Press, 1980

GINSBURG, Tom. Judicial review in new democracies: constitucional courts in asian cases. Cambridge: Cambridge University Press, 2003

GREENHOUSE, Linda. The U.S. Supreme Court: a very short introduction. Oxford: Oxford University Press, 2012

HIRSCHL, Ran. Towards juristocracy: the origins and consequences of the new constitucionalism. Cambridge: Harvard University Press, 2007

POSNER, Richard. How judges think, Cambridge: Harvard University Press, 2010

SANTOS, Clara da Mota. Ativismo judicial e mutação constitucional: uma proposta de reação democrática do controle difuso de constitucionalidade à tese de sua objetivação. Dissertação de mestrado, Universidade de Brasília, 2013

SARAMAGO, José. História do cerco de Lisboa. São Paulo: Companhia das Letras, 2008 
SILVA, Virgílio Afonso da. "O STF e o controle de constitucionalidade: deliberação, diálogo e razão pública”. Revista de Direito Administrativo 250, 2009

SOUZA, Jorge Munhós de. "Diálogo institucional: em algum lugar entre as teorias da supremacia". in As novas faces do ativismo judicial, (André Luiz Fernandes Fellet/ Daniel Giotti de Paula/ Marcelo Novelino, orgs.). Salvador: Editora Juspodivm, 2011

TATE, Neal; VALLINDER, Torbjörn (coord.). The global expansion of judicial power. New York: New York University Press, 1995

TUSHNET, Mark. Taking the Constitution away from the courts. Princeton: Princeton University Press, 2000

TUSHNET, Mark. Why the Constitution matters. New Haven: Yale University Press, 2010

WALDRON, Jeremy. The Core of the Case Against Judicial Review. Yale Law Journal, Vol. 115 (6), 2006

WALDRON, Jeremy. The dignity of legislation. Cambridge: Cambridge University Press, 2007

VERMEULE, Adrian. Law and the limits of reason, New York: Oxford University Press, 2009 